\title{
Morphology and morphometric study of occipital condyles
}

\section{Asra Anjum *1, Gayathri Pandurangam ${ }^{2}$, Supriya Garapati ${ }^{3}$, Naveen Bandarupalli 4 ,} Hajera Rabbani ${ }^{5}$, Divya $\mathbf{P}^{6}$.

${ }^{*_{1}}$ Tutor, Department of Anatomy, Mamata Academy of Medical Sciences, Hyderabad, Telangana State, India.

${ }^{2}$ Assistant Professor, Imam Abdulrahman bin Faisal Univeristy, College of Applied Medical Sciences in Jubail, Respiratory Care Department.

${ }^{3}$ Professor, Department of Anatomy, Mamata Academy of Medical Sciences, Hyderabad, Telangana State, India.

${ }^{4}$ Professor, Department of Anatomy, Mamata Academy of Medical Sciences, Hyderabad, Telangana State, India.

${ }^{5}$ Assistant Professor, Department of Community Medicine, Mamata Academy of Medical Sciences, Hyderabad, Telangana State, India

${ }^{6}$ Assistant Professor, Department of Anatomy, Mamata Academy of Medical Sciences, Hyderabad, Telangana State, India.

\section{ABSTRACT}

Introduction: The occipital condyles are undersurface protruberances of the occipital bone in vertebrates, which articulate with the superior facets of the atlas vertebra. The condyles are oval or reniform in shape, and their anterior extremities directed forward and medially and are closer together than the posterior end.

Aim: The aim of the study is to provide important anatomical parameters for lateral transcondylar approach. Materials and Methods: 200 occipital condyles in 100 dry human skulls ( 73 males and 27 females) were studied. The measured parameters included length, width, height, shape, anterior and posterior intercondylar distance, distance between basion and opesthion, distance from anterior tip of the condyle to the basion and opestion and distance from posterior tip to the basion and opesthion. Measurements were made using Vernier Callipers.

Results: The mean length, width and height of the occipital condyles in males is greater than females. The anterior intercondylar distance is more in females whereas posterior intercondylar distance is more in males. The mean distance from basion to opesthion / anteroposteriordiamerer of foramen magnum is more in males than in females. The mean distance between the anterior tip of occipital condyles to basion is more in females than in males on both the sides.

Conclusion: The knowledge of condylar anatomy helps the surgeon in making important decisions regarding extent and direction of condylar drilling and minimizing injury and retraction of neural structures.

KEY WORDS: Occipital Condyles, Foramen Magnum, Intercondylar distance, Basion, Opesthion.

Corresponding Author: Mrs Asra Anjum, Tutor, Department of Anatomy, Mamata Academy of Medical Sciences, Hyderabad, Telangana State, India. E-Mail: asra.anjum1217@gmail.com

Access this Article online

Quick Response code

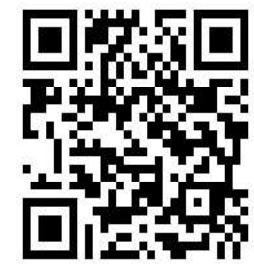

DOI: $10.16965 /$ ijar.2021.107
Journal Information

International Journal of Anatomy and Research

ISSN (E) 2321-4287 | ISSN (P) 2321-8967

https://www.ijmhr.org/ijar.htm

DOI-Prefix: https://dx.doi.org/10.16965/ijar

(cc) $\mathrm{ET}-\mathrm{Na}-\mathrm{si}$
Received: 02 Feb 2021

Peer Review: 02 Feb 2021

Revised: None
Article Information

Accepted: 22 Feb 2021

Published (O): 05 Mar 2021

Published (P): 05 Mar 2021 


\section{INTRODUCTION}

Occipital condyles are the two bony projections that are present in the inferior surface of occipital bone in the skull. The occipital condyle occupies the anterior half of the outer margin of foramen magnum. The articular surface is oval or reniform in outline, faces downward and laterally and articulates with the superior articular facet of the lateral mass of atlas forming the synovial atlanto - occipital joint [1]. The margins gives attachment to the capsule of the atlanto - occipital joints, and on the medial side of each is a rough impression or tubercle for the alar ligament. At the base of condyle, the bone is tunnelled by a short canal, the hypoglossal canal [2]. The stability of the craniovertebral junction depends largely on the morphometric parameters of the occipital condyles. Each occipital condyle is oriented obliquely, so that its anterior end lies closer to the midline. The hypoglossal canal directed laterally and slightly forwards, and jugular foramen is lateral to each condyle [3].

The CVJ refers to an area that includes the foramen magnum (FM), Occipital Condyles (OC's) and the first two cervical vertebrae, namely atlas and axis [4]. The CVJ is associated with many important structures such as the medulla oblongata, upper spinal and lower cranial nerves (glossopharyngeus, vagus, accessories and hypoglossus), vertebral arteries with its branches and vertebral veins, as well as the atlas, axis and occipital bone with important ligamentous and muscular attachments [5]. The study of the anatomy of these structures in clinical pathology and surgery justifies the implementation of new techniques for approaches at this region [6]. Due to its sensitive location, tumors located in the CVJ still have great challenges during their surgical resection. Although these tumors represent only about 1 percent of all intracranial tumors, their resection is extremely difficult [7]. A number of surgical access routes of this region are currently available including transcondylar, supracondylar, anf other lateral surgical approaches. Conventional anatomy and surgical textbooks donot describe the anatomical variations in the OCs. Many such anomalies can be encountered incidentally [8]. The wide difference between the AID and PIDs leads the OC to have different anterior and posterior angles. The anteroposterior orientation and narrow inercondylar space would require a more bony removal [9].

Aim: The aim of the study is to analyse the occipital condylar morphometry. The occipital condylar anatomy assists the surgeon in making important decisions regarding extent and direction of condylar drilling and minimizing injury and retraction of neural structures.

\section{MATERIALS AND METHODS}

The study was carried out in 100 dry adult human skulls ( 73 males and 27 females) from department of Anatomy from medical colleges in Telangana state. Damaged skulls were not included in the study. Sex of each skull was determined by meticulously scrutinizing the classic anatomic features. 200 occipital condyles in 100 dry human skulls (73 males and 27 females) were studied. The measured parameters included length, width, height, shapeanterior and posterior intercondylar distance, distance between basion and opesthion, distance from anterior tip of the condyle to the basion and opestion and distance from posterior tip to the basion and opesthion. Measurements were made using Vernier Callipers (fig 1 and fig 2). The following measurements were noted:

- Length of the occipital condyles (right and left).

- Width of the occipital condyles (right and left).

- Height of the occipital condyles (right and left).

- Shape of the occipital condyle (right and left)

- Anterior intercondylar distance.

- Posterior intercondylar distance.

- Distance from Anterior tip of occipital condyle to basion.

- Distance from Anterior tip of occipital condyle to opesthion.

- Distance from posterior tip of occipital condyle to basion.

- Distance from posterior tip of occipital condyle to opesthion.

- Distance from basion to opesthion. 
Asra Anjum, Gayathri Pandurangam, et al., Morphology and morphometric study of occipital condyles.

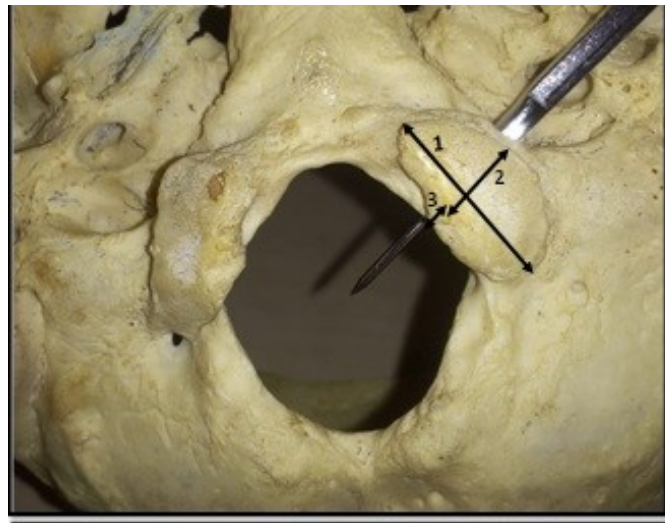

Fig: 1 - some metric param eters of occipital condyle(OC). (1) length of OC. (2) width of OC. (3) height of $O C$

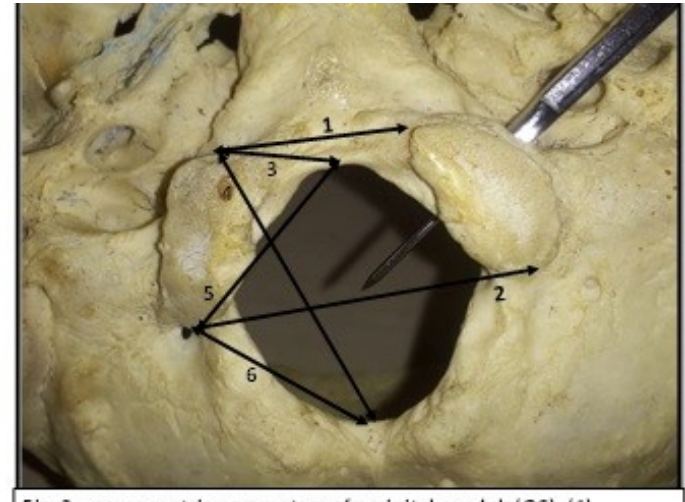

Fig: 2 - some metric parameters of occipital condyle(OC). (1) Anterior intercondylar distance. (2) Posterior intercondylar distance. (3) distance between anterior tip of $\mathrm{OC}$ and basion. (4) distance between anterior tip of $O C$ and Opesthion. (5) distance between posterior tip of $O C$ and basion. (6) distance between posterior tip of $O C$ and Opesthion.

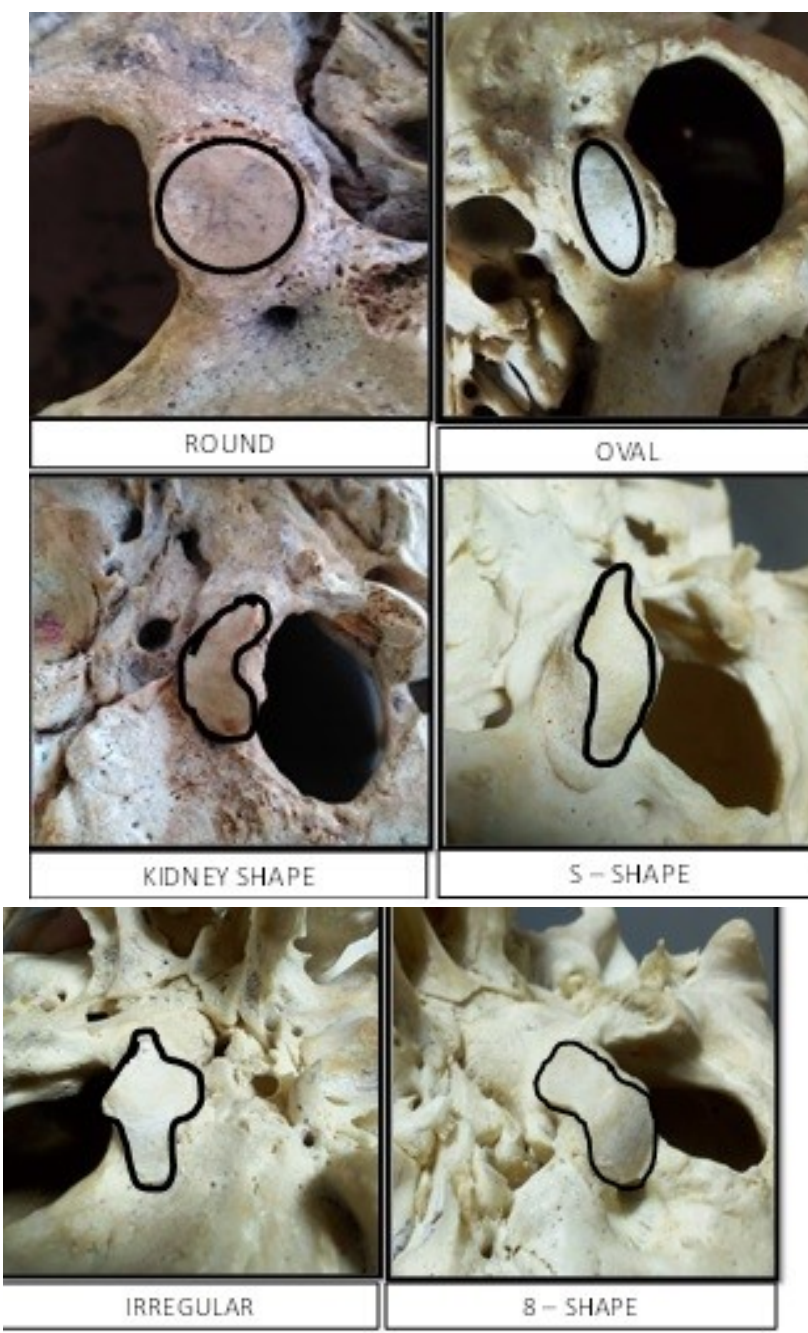

The length of the $\mathrm{OC}$ is measured from the anterior tip to the posterior tip. Width of the $O C$ is measured from the midpoint of lateral margin to the midpoint of the medial margin. Height of the $\mathrm{OC}$ is measured along the thickness of the $\mathrm{OC}$ in the midpoint.

Statistical Analysis: All data was expressed as mean \pm standard deviation (SD) and the level of statistical significance was performed using SPSS VERSION 20.

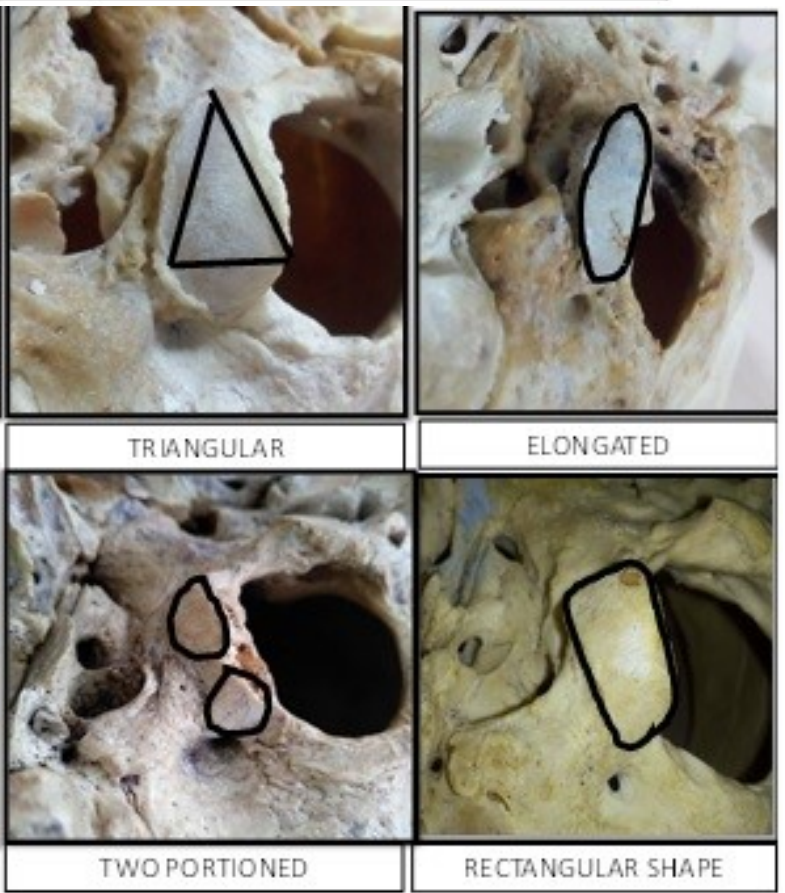

\section{RESULTS}

200 occipital condyles from 100 skulls were investigated among which 73 males and 27 females.

The mean length of the occipital condyles in males is $23.5 \mathrm{~mm}$ on the right side and 23.34 $\mathrm{mm}$ on the left side where as in females 22.44 $\mathrm{mm}$ on right side and $22.62 \mathrm{~mm}$ on left side. The mean width of the occipital condyles in males is $12.19 \mathrm{~mm}$ on right side and $12.29 \mathrm{~mm}$ on the left side, where as in females $11.46 \mathrm{~mm}$ on the right side and $11.87 \mathrm{~mm}$ on the left side. The mean height of the occipital condyles in males is $8.89 \mathrm{~mm}$ on the right side and 8.85 $\mathrm{mm}$ on the left side, where as in females 8.70 $\mathrm{mm}$ on the right side and $8.62 \mathrm{~mm}$ on the left side (Table 1).

The mean distance from anterior tip of $\mathrm{OC}$ to 
basion in females is $10.85 \pm 1.34$ and $10.98 \pm 1.28$ on right and left sides respectively, where as in males the mean distance of anterior tip of OC from basion is $10.57 \pm 1.68$ and $10.90 \pm 10.47$ on right and left sides respectively. The mean distance from anterior tip of OC to opesthion in females is $38.09 \pm 2.74$ and $37.64 \pm 2.96$ on right and left sides respectively, where as in males the mean distance of anterior tip of OC from opesthion is $38.59 \pm 2.55$ and $38.60 \pm 2.55$ on right and left sides respectively. The mean distance from posterior tip of OC to basion in females is $25.92 \pm 1.22$ and $26.18 \pm 1.67$ on right and left sides respectively, where as in males the mean distance of posterior tip of OC from basion is $26.54 \pm 1.98$ and $26.73 \pm 2.24$ on right and left sides respectively. The mean distance from posterior tip of OC to opesthion in females is $26.03 \pm 2.28$ and $26.29 \pm 3.0$ on right and left sides respectively, where as in males the mean distance of posterior tip of OC from opesthion is $27.15 \pm 2.14$ and $27.57 \pm 2.68$ on right and left sides respectively.

The anterior and posterior intercondylar distances in males were found to be $17.86 \mathrm{~mm}$ and $41.27 \mathrm{~mm}$ respectively, where as in females $18.44 \mathrm{~mm}$ and $38.59 \mathrm{~mm}$ respectively. The mean distance from basion to opesthion / anteroposterior diamerer of foramen magnum is $33.78 \mathrm{~mm}$ in males and $33.57 \mathrm{~mm}$ in females. (Table.2)

The incidence of shapes is given in table. 3

Table 1: Parameters of Occipital Condyle.

\begin{tabular}{lcccc}
\hline \multirow{2}{*}{ Parameter } & \multicolumn{2}{c}{ Female (Mean \pm SD) } & \multicolumn{2}{c}{ Male (Mean $\pm S D$ ) } \\
\cline { 2 - 5 } & Right & Left & Right & left \\
\hline Length $(\mathrm{mm})$ & $22.44 \pm 2.01$ & $22.62 \pm 2.41$ & $23.5 \pm 2.71$ & $23.34 \pm 3.06$ \\
Width $(\mathrm{mm})$ & $11.46 \pm 1.56$ & $11.87 \pm 1.45$ & $12.19 \pm 1.53$ & $12.29 \pm 1.47$ \\
Height $(\mathrm{mm})$ & $8.70 \pm 1.12$ & $8.62 \pm 1.10$ & $8.89 \pm 1.02$ & $8.85 \pm 1.13$ \\
\hline
\end{tabular}

Table 2: Morphometric measurements of occipital condyles.

\begin{tabular}{lcccc}
\hline \multirow{2}{*}{\multicolumn{1}{c}{ Parameters }} & \multicolumn{2}{c}{ Female $[$ Mean(mm) $\pm S D]$} & \multicolumn{2}{c}{ Male [Mean(mm) $\pm S D]$} \\
\cline { 2 - 5 } & Right & Left & Right & Left \\
\hline Anterior tip to Basion & $10.85 \pm 1.34$ & $10.98 \pm 1.28$ & $10.57 \pm 1.68$ & $10.90 \pm 1.47$ \\
Anterior tip to Opesthion & $38.09 \pm 2.74$ & $37.64 \pm 2.96$ & $38.59 \pm 2.55$ & $38.60 \pm 2.55$ \\
Posterior tip to Basion & $25.92 \pm 1.22$ & $26.18 \pm 1.67$ & $26.54 \pm 1.98$ & $26.73 \pm 2.24$ \\
Posterior tip to Opesthion & $26.03 \pm 2.28$ & $26.29 \pm 3.0$ & $27.15 \pm 2.14$ & $27.57 \pm 2.68$ \\
Anterior ICD & $18.44 \pm 2.96$ & $17.86 \pm 2.45$ \\
Posterior ICD & $38.59 \pm 4.53$ & $41.27 \pm 4.74$ \\
Basion to Opestion & \multicolumn{2}{c}{$33.57 \pm 2.40$} & $33.78 \pm 2.42$ \\
\hline
\end{tabular}

Int J Anat Res 2021, 9(1.3):7905-11. ISSN 2321-4287
Table 3: Incidence of shapes of oc in males and females.

\begin{tabular}{lcc}
\hline \multicolumn{1}{c}{ Shape } & Male & Female \\
\hline 8 - shaped & $15.1(\%)$ & $11.1(\%)$ \\
Elongated & $16.4(\%)$ & $7.4(\%)$ \\
Irregular & $2.7(\%)$ & $3.7(\%)$ \\
Kidney & $2.8(\%)$ & $3.7(\%)$ \\
Oval & $40(\%)$ & $42.4(\%)$ \\
Round & $1.4(\%)$ & $7.4(\%)$ \\
S - Shaped & $2.7(\%)$ & $12.4(\%)$ \\
Triangular & $11(\%)$ & $7.4(\%)$ \\
Rectangular & $5.5(\%)$ & - \\
Two portioned & $2.5(\%)$ & $4.4(\%)$ \\
\hline
\end{tabular}

\section{DISCUSSION}

The Occipital Condyle is the distinctive bony structure linking the skull and the vertebral column. The OC partly covers the fringe o the foramen magnum anteriorly and form an articulation with the superior articular facets on the lateral masses of the atlas imferiorly. Each $O C$ is oval in outline and oriented obliquely and traversed by hypoglossal canal. A condylar fossa is situated just posterior to the $O C$ and contains a posterior condylar canal for emissary vein from the sigmoid sinus. Laterally the occipital bone connects with the petorus part of the temporal bone anteriorly and mastoid process posteriorly [10].

The knowledge of approximate measurements of occipital condyles and variations in shape will serve as ready reference when surgical interventions are needed. The dimensions of the occipital condyles in this study are significant and comparable with other studies of similar parameters.

From the results obtained in our study it was observed that the mean length of the occipital condyles in males is $23.5 \mathrm{~mm}$ on the right side and $23.34 \mathrm{~mm}$ on the left side where as in females $22.44 \mathrm{~mm}$ on right side and 22.62 $\mathrm{mm}$ on left side. The measurements were greater in male skulls than in female skulls on both the sides. The present study is correlated with the study done by Swapnali Shamkuwar et al [11] who reported the mean length of OC in males is $2.33 \mathrm{cms}$ on the right side and $2.31 \mathrm{cms}$ on the left side where as in females $2.23 \mathrm{cms}$ on the right side and $2.21 \mathrm{cms}$ on the left side. And also correlated with to what was found by previous authors as $2.3 \mathrm{~cm}$ [9, $12,13,14,15]$. In the stydy by Bayat et al [16] 
the mean length of left occipital condyle was $19.28 \mathrm{~mm}$ and right occipital condyle was 19.43 $\mathrm{mm}$. these findings were observed lesser than our present study findings. In the study done by Oliviera et al [17] the mean OC length in males is $26.74 \mathrm{~mm}$ on the right side and $26.85 \mathrm{~mm}$ on the left side, where as in females $25.45 \mathrm{~mm}$ on the right side and $24.64 \mathrm{~mm}$ on the left side. These findings of Oliviera et al were higher than our present study findings. In our study, we also observed that women tend to have shorter $O C$ than men.

The mean width of the occipital condyles in males is $12.19 \mathrm{~mm}$ on right side and $12.29 \mathrm{~mm}$ on the left side, where as in females $11.46 \mathrm{~mm}$ on the right side and $11.87 \mathrm{~mm}$ on the left side. The present study is similar with the findings of Swapnali Shamkuwar et al [11] who reported the mean width of the $O C$ in males is $12.9 \mathrm{~mm}$ on both the sides, where as in females $12.5 \mathrm{~mm}$ on the right side and 12.7 on the left side. The mean measurements in male skulls were slightly higher than the female skulls. Other researchers reported slightly higher values, in which the mean width of the OCs is $12.97 \mathrm{~mm}$ (by Sandeep Saluja et al) [18], $12.81 \mathrm{~mm}$ (by salih AM et al) [19], $13.1 \mathrm{~mm}$ (by Kizilkant ED et al) [20]. In the present study we found the mean width of OCs is narrow in females than in males which is in contrast with the study done by Sneha GK et al [9] who reported that males tend to have narrow $\mathrm{OC}$ than female.

The mean height of the occipital condyles in males is $8.89 \mathrm{~mm}$ on the right side and 8.85 $\mathrm{mm}$ on the left side, where as in females 8.70 $\mathrm{mm}$ on the right side and $8.62 \mathrm{~mm}$ on the left side. The thickness of $\mathrm{OC}$ also matters during condylectomy as one should know how deep OC has to be drilled. This measured height is approximate to the result obtained byOliver $G$ et al [21] who reported the height as $8.8 \mathrm{~mm}$. The values are higher in the studies done by M. Mahamutha A et al [2] who reported the mean height of the $O C$ on the right side is $9.6 \mathrm{~mm}$ and $9.5 \mathrm{~mm}$ on the left side.

The OCs were found to converge ventrally. The anterior and posterior intercondylar distances in males were found to be $17.86 \mathrm{~mm}$ and $41.27 \mathrm{~mm}$ respectively, where as in females
$18.44 \mathrm{~mm}$ and $38.59 \mathrm{~mm}$ respectively. This study is in accordance with the findings of Vishal RJ et al [22] who reported the AICD as $18.23 \mathrm{~mm}$ in males and $19.11 \mathrm{~mm}$ in females.This study is also similar with the findings of Shimaa et al [23] who reported the anterior and PICDs as $18.97 \mathrm{~mm}$ and $38.39 \mathrm{~mm}$ respectively. These measured distances are lower than the results obtained by Kizilkant [24], Naderi. S [13], Fetouh F A [15] who reported AID as $22.6 \mathrm{~mm}$, $21 \mathrm{~mm}, 20 \mathrm{~mm}$ and PID as $44.2 \mathrm{~mm}, 41 \mathrm{~mm}$, $41 \mathrm{~mm}$ respectively. The measured distances are higher than the results obtained by DeepaSomanath et al [25] who reported Anterior and PICDs as $15.2 \mathrm{~mm}$ and $27.7 \mathrm{~mm}$ respectively.

In the present study the mean distance from basion to opesthion / antero posterior diamerer of foramen magnum is $33.78 \mathrm{~mm}$ in males and $33.57 \mathrm{~mm}$ in females. This study coinsides with the study done by Vishal RJ et al [22] who reported the anteroposterior diameter $34.24 \mathrm{~mm}$ in males and $33.97 \mathrm{~mm}$ in females. The measured distance is higher than the results obtained by Gaurav Agnihotrri et al [26] who reported the anteroposterior diameter of foramen magnum as $32.83 \mathrm{~mm}$. And lower than the results obtained by Sayed [27] and Aziz[28] who reported the anteroposterior diameter of foramen magnum as $36.22 \mathrm{~mm}$ and $35.94 \mathrm{~mm}$ respectively.

The mean distance between the anterior tip of OC to basion on the right side was $10.57 \mathrm{~mm}$ and $10.85 \mathrm{~mm}$ in males and females respectively, and $10.90 \mathrm{~mm}$ and $10.98 \mathrm{~mm}$ respectively on the left side. The mean distance between the posterior tip of $\mathrm{OC}$ to basion on the right side was $26.54 \mathrm{~mm}$ and $25.92 \mathrm{~mm}$ in males and females respectively, and $26.73 \mathrm{~mm}$ and $26.18 \mathrm{~mm}$ respectively on the left side. These measured distances are similar to the results obtained by Fetouh et al [15] as $16 \mathrm{~mm}$ and $27 \mathrm{~mm}$ respectively and by Naderi et al [13] who reported them as $10 \mathrm{~mm}$ and $28 \mathrm{~mm}$ respectively, and by Sneha GK et al [9] who reported them as $12 \mathrm{~mm}$ and $27 \mathrm{~mm}$ respectively.

The mean distance between the anterior tip of $O C$ to opesthion on the right side was $38.59 \mathrm{~mm}$ and $38.09 \mathrm{~mm}$ in males and females 
Table 4: Comparison of incidence of different shapes of occipital condyles with other studies.

\begin{tabular}{lcccccccccc}
\hline \multirow{2}{*}{ Shape } & \multicolumn{2}{c}{ Present study (\%) } & \multicolumn{2}{c}{ Sneha G K et al (\%) } & \multicolumn{2}{c}{ Varsha T S et al (\%) } & \multicolumn{2}{c}{ Swapnali S et al (\%) } & \multicolumn{2}{c}{ Ilhan p et al(\%) } \\
\cline { 2 - 11 } & Male & Female & Male & Female & Male & Female & Male & Female & Total \\
\hline 8 - shaped & 15.1 & 11.1 & 29 & 22.5 & 24 & 12 & 5.4 & - & - \\
Elongated & 16.4 & 7.4 & - & - & - & - & - & - & - \\
Irregular & 2.7 & 3.7 & 11.8 & 11.3 & 4 & 2 & 3 & 1.7 & 22 \\
Kidney & 2.8 & 3.7 & 11.8 & 12 & 8 & 8 & 13 & 18.4 & - \\
Oval & 40 & 42.4 & 21.8 & 22.5 & 16 & 30 & 36.6 & 34.6 & 10 \\
Round & 1.4 & 7.4 & - & 1.4 & 2 & 2 & - & - & 6 \\
S - Shaped & 2.7 & 12.4 & 13.6 & 14.8 & 20 & 16 & 17.4 & 18 & - \\
Triangular & 11 & 7.4 & 9 & 10.6 & 24 & 12 & 12 & 24.2 & - \\
Rectangular & 5.5 & - & - & - & 2 & 14 & 3.6 & 1.8 & 24 \\
Two portioned & 2.5 & 4.4 & 2.7 & 4.9 & - & 4 & 4.2 & 2.5 & - \\
\hline
\end{tabular}

respectively, and $38.60 \mathrm{~mm}$ and $37.64 \mathrm{~mm}$ respectively on the left side. The mean distance between the posterior tip of OC to opesthion on the right side was $27.15 \mathrm{~mm}$ and $26.03 \mathrm{~mm}$ in males and females respectively, and $27.57 \mathrm{~mm}$ and $226.29 \mathrm{~mm}$ respectively on the left side. This is in agreement with Naderi et al [13] who reported them as $39 \mathrm{~mm}$ and $26 \mathrm{~mm}$ respectively and Fetouh et al [15] who reported it as $50 \mathrm{~mm}$ and $27 \mathrm{~mm}$.and by Sneha GK et al [9] who reported them as $39 \mathrm{~mm}$ and $28 \mathrm{~mm}$ respectively. The distance between the posterior tip of $\mathrm{OC}$ and the opisthion is important as it represents the width of surgical exposure in suboccipital craniotomy and larger the distance better is the access for the posterolateral approach [9].

The shape of OC was classified into different types. The most common type was oval in both males and females, whereas the most unusual type was two-portioned, round, s-shaped, kidney shaped and irregular in males, where as in females it was two-portioned, kidney, irregular, round and elongated. This study is compared with the studies done by Sneha G K et al [9], Varsha T S et al [29], Swapnali S et al [11] and Ilhan $p$ et al [30].

\section{CONCLUSION}

The findings of this study provides a database for choosing the right surgical approach to minimize the mortality and morbidity in this region. The preoperative radiological evaluation through plain radiography, CT and MRI are important for achieving surgical success and this evaluation is required before surgery to prevent complications like hemorrhage, atlantooccipital instability and injury to major structures passing through Foramen
Magnum. The data obtained from the present study will be useful not only to neurosurgeons and orthopeditians but also to the anthroplolgists, morphologists and clinical anatomists.

\section{ACKNOWLEDGEMENTS}

I most humbly acknowledge the institutions who allowed me to take measurements of the bones. Authors of this study also acknowledge to authors, editors and publishers of all those articles, journals and books from where the literature for this articles has been reviewed and discussed.

\section{Conflicts of Interests: None}

\section{REFERENCES}

[1]. Asim Kumar Datta. Essentials of Human Anatomy Head and Neck Part II. $6^{\text {th }}$ ed. April 2017. P.46.

[2]. M. Mahamutha Affshana, Dr. Yuvraj. Analysis of the Occipital Condyl. J. Pharm. Sci. \& Res. 2015;7(7):439-440.

[3]. Vishteh AG, Crawford NR, Melton MS, Spetzler RF, Sonntag VK, Dickman CA. Stability of the craniovertebral junction after unilateral occipital condyle resection: A biomechanical study. J Neurosurg. 1999;90:91-8.

[4]. Ha W, Yang D, Gu S, et al. Anatomical study of sub occipital vertebral arteries and surrounding bony structures using virtual reality technology. Med Sci Monit. 2014;20:802 806.

[5]. Rhoton AL, de Olivera JE, Peace D. Microsurgical anatomy of the region of the foramen magnum. Surg Neurolog. 1985;24(3):293 352.

[6]. G. Agnihotri, D. Mahajan, and A. Sheth. An anatomical perspective of human occipital condyles and foramen magnum with neurosurgical correlates. Jemds 2014;3(17):4479-4503.

[7]. S. Khaoroptham, P. Jittapiromsak, R. Siwanuwatn, and K.Chantra. The outcome of surgical treatment for tumors of the craniocervical junction. J. Med. Assoc. Thai. 2007;90(7):1450-1457. 
[8]. D. Lang, G. Neil-Dwyer, and F. lannotti. The suboccipital transcondylar approach to the clivus and craniocervical junction for ventrally placed pathology at and above the foramen magnum. Acta neurochirurgica 1993;125(1):132-137.

[9]. SnehaGuruprasadKalthur, SupriyaPadmashali, Chandni Gupta, and Antony S. Dsouza. Anatomic study of the occipital condyle and its surgical implications in transcondylar approach. J Craniovertebr Junction Spine. 2014 Apr-Jun;5(2):71-77.

[10]. Standring S, Editor. Gray's Anatomy: The Anatomical Basis of Clinical Practice. $40^{\text {th }}$ Ed. Scotland: Churchill Livingstone Elsevier; 2008.

[11]. Swapnali Shamkuwar, Varsha Mokhasi. Morphometry And Morphology Of Occipital Condyle Related To The Transcondylar Approach In Dry Skulls. Int J Anat Res 2018;6(4.1):5820-34.

[12].Muthukumar N, Swaminathan R, Venkatesh G, Bhanumathy SP. A morphometric analysis of the foramen magnum region as it relates to the transcondylar approach. ActaNeurochir (Wien) 2005;147:889-95.

[13]. Naderi S, Korman E, Citak G, Güvençer M, Arman C, Senoglu M, et al. Morphometric analysis of human occipital condyle. ClinNeurolNeurosurg. 2005;107:191-9.

[14]. Kizilkanat E. Morphometry of the hypoglossal canal, occipial condyle and foramen magnum. Neurosurg Q. 2006;16:121-5.

[15]. Fetouh FA, Awadalla AM. Morphometric analysis of the occipital condyle and its surgical implications in transcondylar approach. The pan arab neurosurgery society. about 15 p. http://panarabjn.org/wpcontent/uploads/2013/03.

[16]. Parvindokht Bayat, Mahdie Bagher, Ali Ghanbari, Amir Raoofi. Characterization of occipital condyle and comparison of its dimensions with head and foramen magnum circumferences in dry skulls of Iran. Int. J. Morphol 2014;32(2):444-448.

[17]. Oliveira O.F, Tinoco R.L.R, Daruge J.E, Araujo. L. G, Silva, R.H.A \& Paranhos. L,R. Sex determination from occipital condylar measurements by baudoin index in forensic porpoises. Int. J. Morphol. 2013;31(4):1297-1300.

[18]. Sandeep Saluja, Sushant Swaroop Das, Neelam Vasudeva. Morphometric Analysis of the Occipital Condyle and Its Surgical Importance. Journal of Clinical and Diagnostic Research. 2016 Nov;10(11):AC01-AC04.

[19]. Salih AM, Ayad CE, Abdalla EA. Characterization of occipital condyles in sudanese using computerized tomography. Glo Adv Res J Med Med Sci. 2014;3(12):437- 44.
[20]. Kizilkanat ED, Boyan N, Soames R, Oguz O. Morphometry of the hypoglossal canal, occipital condyle, and foramen magnum. Neurosurgery Quarterly. 2006;16(3):121-25.

[21]. Oliver G: Biometry of the human occipital bone. J Anat 1975;120:507-518.

[22]. Vishal Ramesh Jasuja, Prasad G. Kulkarni, Shabana M.Borate, Silky R. Punyani. A morphometric Study Of Occipital Condyles And Foramen Magnum In Adult Skull Base In Western Maharashtra Region Of India: Int J Anat Res 2016;4(1):1846-50. ISSN 2321-4287.

[23]. Shimaa Anter Farid, Islam Omar Abdel Fattah. Morphometric Study of Human Adult Occipital Condyle, Hypoglossal Canal and Foramen Magnum in Dry Skull of Modern Egyptians. International Journal of Clinical and Developmental Anatomy. 2018;4(1):19-26.

[24]. Kizilkanat E: Morphometry of the hypoglossal canal, occipital condyle and foramen magnum. Neurosurgery Quarterly 2006;16(3):121-125.

[25]. Deepa Somanath, Sudha R. Morphometry Of Occipital Condyles In Craniovertebral Surgeries: Int J Anat Res 2017;5(1):3552-55. ISSN 2321-4287.

[26]. Gaurav Agnihotri, Divya Mahajan, Abha Sheth. "An Anatomical Perspective Of Human Occipital Condyles And Foramen Magnum With Neurosurgical Correlates". Journal Of Evolution Of Medical And Dental Sciences 2014;3(17):4497-4503, DOI: 10.14260/Jemds/2014/2465.

[27]. W. M. Sayed, and I. F. Gaballah. A study of the dimensions of both the foramen magnum and occipital condyles in modern Egyptians and their use in sex determination. Egyptian J. of Anatomy 2015;38(1):29-42.

[28]. J. N. S. Aziz, and M. Youakim. Morphological study of the foramen magnum and occipital condyle and its surgical implications in transcondylar approach. Libyan J. Med. Res. 2016;10(1): 70-82.

[29]. Varsha. T. Sholapurkar, R.D.Virupaxi, S.P. Desai. Morphometric Analysis Of Human Occipital Condyles For Sex Determination In Dry Adult Skulls: Int J Anat Res 2017;5(1):3318-23.

[30]. Pelin Ilhan, Buse Kayhan, Mete Erturk, Gulgun Sengul. Morphological analysis of occipital condyles and foramen magnum as a guide for lateral surgical approaches: MOJ Anat Physiol. 2017;3(6):188 194.

\section{How to cite this article:}

Asra Anjum, Gayathri Pandurangam, Supriya Garapati, Naveen Bandarupalli, Hajera Rabbani, Divya P. Morphology and morphometric study of occipital condyles. Int J Anat Res 2021;9(1.3):7905-7911. DOI: 10.16965/ijar.2021.107 